\title{
CORRELATION OF LH AND FSH WITH SPERM ANALYSIS IN INFERTILE MALES
}

\author{
M. Roopalatha ${ }^{1}$, B. Preethi², C. Ramakrishna 3 , S. Sanjeevi Rao ${ }^{4}$, A. Anuradha ${ }^{5}$, C. H. Venkatesh 6
}

${ }^{1}$ Associate Professor, Department of Biochemistry, NRI Institute of Medical Sciences, Sanghivalasa, Visakhapatnam. ${ }^{2}$ Assistant Professor, Department of Biochemistry, NRI Institute of Medical Sciences, Sanghivalasa, Visakhapatnam. ${ }_{3}^{3}$ Assistant Professor, Department of Biochemistry, NRI Institute of Medical Sciences, Sanghivalasa, Visakhapatnam. ${ }^{4}$ Professor and HOD, Department of Biochemistry, NRI Institute of Medical Sciences, Sanghivalasa, Visakhapatnam. ${ }^{5}$ Research Scholar, Department of Human Genetics, Andhra University, Visakhapatnam.

${ }^{6}$ Statistician, Seven Hills Hospital, Visakhapatnam.

\section{ABSTRACT}

\section{BACKGROUND}

Infertility has been defined as the inability of sexually active couple to achieve pregnancy despite of unprotected intercourse for a period of greater than 12 months. The failure of pituitary to secrete FSH and LH will result in disruption of testicular function resulting infertility. Analysis of semen and hormone evaluation are essential parameters in giving a definitive diagnosis in infertile males. The aim of the present study was to evaluate FSH and LH levels and correlate with sperm count, smoking, and alcohol intake in infertile men.

\section{MATERIALS AND METHOD}

All the necessary formalities were taken in maintaining the confidentiality of the patient's samples and ethical clearance from the Ethical Committee of Seven Hills Hospital, Visakhapatnam and NRIIMS, Sangivalasa, was taken. The present study was a prospective cross-sectional one carried out in Seven Hills Hospital and NRI Institute of Medical Sciences, Sangivalasa, Visakhapatnam. FSH, LH, Sperm analysis were done in 50 infertile males (38 were azoospermic and 12 were oligospermiac).

\section{RESULTS}

The association of smoking and alcohol with infertility showed statistical insignificance. There was significant increase in serum concentrations of Follicle Stimulating Hormone $(\mathrm{FSH})$ Levels $(\mathrm{P}=0.001)$ and serum concentrations of Luteinizing Hormone $(\mathrm{LH})$ Levels $(\mathrm{P}=0.004)$.

\section{CONCLUSION}

The present study showed that the high level of gonadotropins is an indication of testicular problems as the cause of infertility.

\section{KEYWORDS}

LH and FSH, Infertile Males, Sperm Analysis.

HOW TO CITE THIS ARTICLE: Roopalatha M, Preethi B, Ramakrishna C, et al. Correlation of LH and FSH with sperm analysis in infertile males. J. Evolution Med. Dent. Sci. 2016;5(68):4897-4900, DOI: 10.14260/jemds/2016/1113

\section{INTRODUCTION}

Infertility has been defined as the inability of sexually active couple to achieve pregnancy despite unprotected intercourse for a period of greater than 12 months.[1] Among the various known pathologies that torment humans, infertility has special place. Though, it does hamper the daily life and usually does not result in physical morbidity, pain, limitation of activity, or longevity, its impact on the psychological and social wellbeing of not only the index patient, but also his or her partner makes it a major issue for health professionals. In the US, more than four in five practicing urologists admit to treating infertility. Accounting for its high prevalence and outspread impact, India has been included it as a part of the national program for reproductive and child health. ${ }^{[2]}$

Financial or Other, Competing Interest: None.

Submission 07-05-2016, Peer Review 11-08-2016,

Acceptance 17-08-2016, Published 24-08-2016.

Corresponding Author:

Dr. M. Roopalatha,

Flat No. 402, Sai Sri Keshav Vihar,

House No.9-19-18,

Street No.24,

CBM Compound,

Near Timpany School,

Vishakapatnam-530003.

E-mail: doctorroopalatha@gmail.com

DOI: $10.14260 /$ jemds/2016/1113
Anterior pituitary secretes FSH and LH. The name FSH and LH is based on the action of hormones in females whereas in males FSH stimulates the Sertoli cells of testis and thereby promotes spermatogenesis and LH stimulates the Leydig cells to secrete testosterone. That is why LH is also called interstitial cell stimulating hormone.[3] Hypothalamic GnRH controls the production of the pituitary gonadotropins $\mathrm{LH}$ and FSH. GnRH is released in discrete pulses for every 2 hours approximately resulting in corresponding pulses of $\mathrm{LH}$ and FSH. These dynamic hormone pulses to a certain degree report for the wide variations in $\mathrm{LH}$ and testosterone even within same individual LH.[4]

Serum FSH elevations are indicative of disturbances in spermatogenesis such as primary testicular failure (hypergonadotropic hypogonadism), although normal FSH levels do not dismiss spermatogenic failure. [5] Smoking is associated with decline in basic semen parameters such as sperm concentration, viability, forward motility, and morphology[6,7] as well as declines in sperm penetration ability and hence fertilisation rates.[8] Although, long-term abuse of alcohol is associated with global suppression of the hypothalamic-pituitary gonadal axis and spermatogenesis, moderate intake is not associated with significant diminution in fertility.[9] Semen analysis and hormone evaluation are of paramount importance in giving a definitive diagnosis in infertile males.[10] Therefore, hormones measurement can help to determine whether the patient has deficiency of 
gonadotropin, primary testicular failure, spermatogenic failure, or androgen resistance. So, the present study aims to evaluate the levels of LH and FSH and correlate with sperm count, smoking, and alcohol intake in infertile men.

\section{MATERIALS AND METHODS}

The study was a prospective cross-sectional one carried out in the Seven Hills Hospital, Ram Nagar and NRI Institute of Medical Sciences, Sanghivalasa, Visakhapatnam. 50 infertile males (age group 25-40 years) with least 3 years' duration of infertility coming for evaluation to Seven Hills Hospitals during July 2014 to July 2015 were selected as subjects and were consented to complete a comprehensive questionnaire relating to their medical and personal history, lifestyle habits, and exposure to gonadotoxins (such as radiation therapy and drugs used for cancer chemotherapy). 25 age-matched controls with proven fertility were selected as control group. Semen was collected from the infertile subjects by masturbation after having abstained from sexual intercourse for a minimum of two days and a maximum of seven days in a private room near the laboratory in order to limit the exposure of the semen to fluctuations in temperature and also to control the time between collection and analysis. The collection was done into a clean, dry, wide-mouthed container made of glass that is non-toxic for spermatozoa. The specimen container was kept in an incubator at $30^{\circ} \mathrm{C}$ temperature.

The estimation of sperm counting was done using the Neubauer haemocytometer chamber. Sperm analysis was carried out according to the World Health Organisation guidelines.(11) Based on the sperm count, the subject were classified as normospermia ( $>20$ million sperm $/ \mathrm{mL})$, oligospermia ( $<20$ million sperm $/ \mathrm{mL}$ ), and azoospermia (no spermatozoa). In proven fertile controls, the sperm count ranged from 20-120 million sperm/mL. $10 \mathrm{~mL}$ fresh blood sample was aseptically collected from antecubital vein of each subject transferred into a clean plain labelled tube allowed to clot and then centrifuged at $6000 \mathrm{rpm}$ for 5 minutes at room temperature. The clear serum was separated and kept at $20^{\circ} \mathrm{C}$ till assayed. Serum concentrations of Follicle-Stimulating Hormone (FSH), Luteinizing Hormone (LH) were measured by IMMULITE 1000 using the kits supplied by Siemens. The association of smoking and alcohol habits were analysed using chi-square test with statistical package for Social Sciences Software and the means of FSH and LH were compared and pvalue is obtained by GraphPad.

\section{RESULTS}

Out of 50 infertile men, 38 (76\%) were azoospermic, 12 (24\%) were oligozoospermic. Frequency of alcoholics and smokers in infertile males were $41(82 \%)$ and $28(56 \%)$ whereas in proven fertile males, 28 (56\%) and 19 (76\%), respectively.

Table 1 demonstrates the distribution and association of smokers in infertility cases and controls. The chi-square statistic is 2.8495. The p-value is 0.0914 . This result is not significant at $\mathrm{p}<0.05$.
Table 2 shows the distribution and association of alcoholics in infertility cases and controls. The chi-square statistic is 0.0465 . The $\mathrm{p}$-value is 0.829222 . This result is not significant at $\mathrm{p}<0.05$.

Table 3 explains serum concentrations of FSH and LH levels in infertile and fertile men groups. The mean FSH and LH levels in azoospermic infertile men were $21.741 \pm 4.17$ and $20.888 \pm 4.38$ respectively whereas in oligospermic infertile males the mean FSH and LH levels were $17.387 \pm 2.19$ and $13.523 \pm 5.46$ respectively as against $5.245 \pm 1.62$ and $4.379 \pm 1.66$ in controls respectively.

The mean and std. dev. of serum FSH and LH levels in infertile and control groups are presented in tables 4. FSH and LH levels showed significant increased $(p>0.05)$ in infertile men when compared with the controls.

\begin{tabular}{|c|c|c|c|}
\hline & Smokers & Non-Smokers & P-Value \\
\hline Cases & $28(31.33)[0.35]$ & $22(18.67)[0.6]$ & \multirow{2}{*}{0.0914} \\
\hline Controls & $19(15.67)[0.71]$ & $6(9.33)[1.19]$ & \\
\hline \multicolumn{4}{|c|}{ Table 1: Association of Smokers with Infertility Cases } \\
and Controls \\
\hline
\end{tabular}

${ }^{*} \mathrm{p}<0.01$-Significant; ${ }^{* *} \mathrm{p}<0.02$-Moderately significant; ${ }^{* * *} \mathrm{p}<0.005$-Highly Significant, NS-Not significant.

\begin{tabular}{|c|c|c|c|}
\hline & Alcoholics & Non-Alcoholics & P-Value \\
\hline Cases & $41(41.33)[0]$ & $9(8.67)[0.01]$ & \multirow{2}{*}{0.8292} \\
\hline Controls & $21(20.67)[0.01]$ & $4(4.33)[0.03]$ & \\
\hline \multicolumn{4}{|c|}{ Table 2: Association of Alcoholics with Infertility Cases } \\
and Controls \\
\hline
\end{tabular}

${ }^{*} \mathrm{p}<0.01$-Significant; ${ }^{* *} \mathrm{p}<0.02$-Moderately Significant; $* * * \mathrm{p}<0.005$-Highly Significant, NS-Not significant.

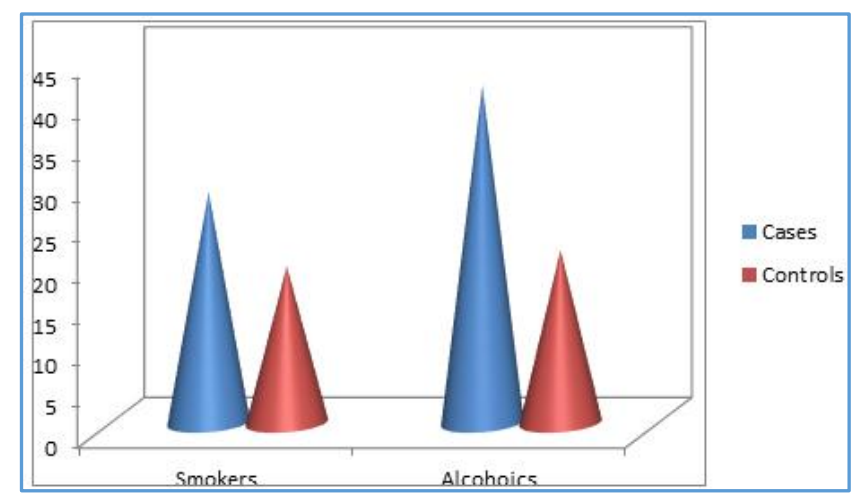

Fig. 1: Frequency Distribution of Smokers and Alcoholics in Infertile Cases and Controls

\begin{tabular}{|c|c|c|c|}
\hline $\begin{array}{c}\text { Infertile and } \\
\text { Fertile Men } \\
\text { Groups }\end{array}$ & Numbers & Hormone Levels Mean+SD \\
\cline { 3 - 4 } & & FSH & LH \\
\hline Azoospermia & 38 & $21.741 \pm 4.17$ & $20.888 \pm 4.38$ \\
\hline Oligospermia & 12 & $17.387 \pm 2.19$ & $13.523 \pm 5.46$ \\
\hline Fertile Men & 25 & $5.245 \pm 1.62$ & $4.379 \pm 1.66$ \\
\hline Table 3: Serum Concentrations of FSH and LH Levels in \\
Infertile and Fertile Men Groups \\
\hline
\end{tabular}

\begin{tabular}{|c|c|c|c|c|}
\hline Parameters & Infertile Group (n=50) & Fertile Group(n=25) & 95\% CI & P-Value \\
\hline FSH & $20.722 \pm 4.18$ & $5.245 \pm 1.625$ & 17.2096 to -13.7444 & $<0.0001$ \\
\hline LH & $19.146 \pm 0.92$ & $4.379 \pm 1.668$ & 15.3615 to -14.1725 & $<0.0001$ \\
\hline \multicolumn{5}{|c|}{ Table 4: Mean \pm SD of FSH and LH Parameters in the Infertile Cases and Controls } \\
\hline
\end{tabular}




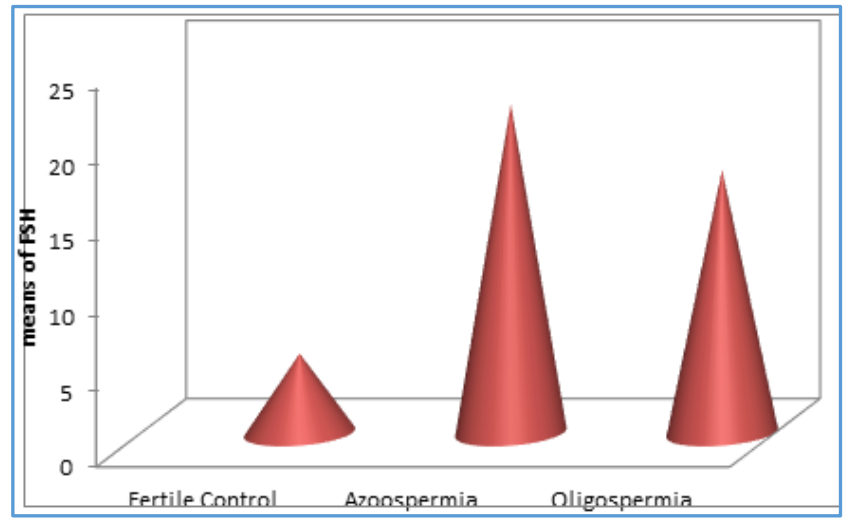

Fig. 2: Distribution of FSH Mean Levels in Infertile Cases and Controls

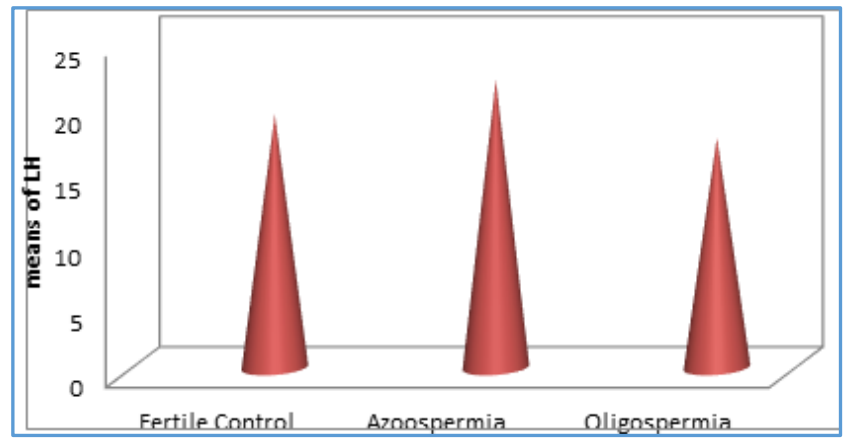

Fig. 3: Distribution of LH Mean Levels in Infertile Cases and Controls

\section{DISCUSSION}

Infertility remains a global health problem with an increasing incidence. It is generally defined as one year of unprotected intercourse without conception. Approximately, 85-90\% of healthy young couples conceive within one year. Infertility affects $10-15 \%$ of couples is an important part of investigation and helps the couple to have children (Mosher L et al 1991).

Ascertaining the reproductive hormone levels is utmost important in the evaluation of male infertility. Emokpae MA et al 2007 reported that these hormones have an important role in male spermatogenesis. ${ }^{[12]}$ LH, FSH evaluation is useful in the management of male infertility.[13] FSH is necessary for initiation of spermatogenesis and maturation of spermatozoa. In the infertile men, higher concentration of FSH is regarded to be a reliable indicator of germinal epithelial damage and was proven to be associated with azoospermia and severe oligozoospermia.[14] De Kretser et al[15] reported inflated levels of serum FSH with increasing severity of seminiferous epithelial destruction. In the present study, gonadotropin (FSH and $\mathrm{LH}$ ) levels were elevated significantly in infertile males when compared with the levels in proven fertile controls, which are in accordance with the studies of Sulthan et al,[16] Zabul et al,[13] Weinbaurer and Nieschlag.[17] A Subhan et al,[18] Ramesh Babu et al,[19] and Dhananjay et al[20] studies, which stated similar results of elevated levels of both folliclestimulating hormone and luteinizing hormones in infertile males. Elevated levels of LH in oligospermic and azoospermic males when compared to normal fertile men were also reported.[21] In germ cell development, FSH, LH, and testosterone are prime regulators and the quantitative production of spermatozoa generally needs the presence of FSH, LH, and testosterone in which FSH acts directly on the seminiferous tubules whereas luteinizing hormone stimulates spermatogenesis indirectly via testosterone. FSH plays a major role in stimulating mitotic and meiotic DNA synthesis in spermatogonia.[22] The overall results clearly indicate significant increase in gonadotropins (FSH and $\mathrm{LH}$ ) in all the subgroups (azoospermia, oligozoospermia). The observed increase in the FSH and LH levels are to stimulate the Sertoli and Leydig cells for proportionate synthesis and secretion of testosterone thereby enhancing spermatogenesis. With advancement of age, decline in testosterone, and inflation in gonadotrophins are associated with a decrease in sperm production and number of normal sperm.[23]

Among many factors which lowers reproductive functions, excessive intake of alcohol has been considered seriously in males. Jensen et al (1988), S. Samal et al (2012) stated that the complete cessation of alcohol consumption is associated with improved fertility. Durphy et al (1991) suggested that chronic alcoholism can cause testicular atrophy leading to oligospermia or azoospermia and also cause ejaculatory dysfunction. In the present study, the relationship between alcohol consumption and abnormalities of semen was not evident and are in contrast with the findings of the above authors.[24-27] Ejaculatory dysfunction can also result from chronic alcoholism.(28-29)

In India, cigarette smoking is highly prevalent among men in the age group of 25-35. The effect of smoking on male reproduction has also been studied where semen quality was investigated in different cross-sectional studies including infertile patients with conflicting results. In males, it has been reported that cigarette smoking have negative effects on every system involved in the reproductive process. Spermatozoa from smokers have less fertilising capacity and embryos display lower implantation rates. ${ }^{30,31}$ Most of the studies reported that the effect of cigarette smoking on levels of male reproductive hormones; however, the findings still remain disputed. Though, the current study not shown a reduction in male fertility associated with smoking, smokers should quit smoking for the sense of responsibility for their future generation as tobacco smoke contains numerous mutagenic substances.

It is established that membrane damage and the formation of Leydig cell autoantibodies are due to excessive alcohol intake, which effects Leydig cell function by reducing testosterone synthesis and its metabolite, acetaldehyde. Also, it disturbs hypothalamopituitary function, further worsening testicular and sexual function. Impotence is a well-known effect of alcoholism as are the signs of hyperoestrogenism, which is probably secondary to disturbances of the metabolism of testosterone and oestrogens in the cirrhotic liver.(28-29)

\section{CONCLUSION}

From this study, it may be concluded that high plasma levels of gonadotropins, low sperm count are pathognomonic of male infertility. The high level of gonadotropins is an indication of testicular problems as the cause of infertility in studied subjects. However, further studies are recommended in large sample to evaluate the levels of gonadotropins and confirm the indication in infertile males. 


\section{REFERENCES}

1. WHO 2000. WHO manual for the standardised investigation and diagnosis of infertile couple. Cambridge, UK: Cambridge University Press.

2. Kumar R. Male infertility-current concepts. Indian Journal of Urology 2011;27(1):39-40.

3. Bijlani RL, Manjunatha S. Hypothalamic and pituitary hormones. Understanding medical physiology. $4^{\text {th }}$ ed. New Delhi: Jaypee Brothers Medical Publishers Ltd 2011:40663.

4. Bhasin SJ, Jameson L. Disorders of the testis and male reproductive system. In: Longo DL, Fauci AS, Kasper DL, et al, eds. Harrison's Principals of Internal Medicine. 18th ed. New York: McGraw-Hill 2012:3010-27.

5. Sabanegh E, Agarwal A. Male infertility. Campbell-Walsh Urology. In: Weiss AJ, Kavoussi LR, eds. $10^{\text {th }}$ ed. Vol.1. 2012:617-47.

6. Vine MF, Tse CK, Hu P, et al. Cigarette smoking and semen quality. Fertil Steril 1996;65(4):835-42.

7. Kunzle R, Mueller MD, Hanggi W, et al. Semen quality of male smokers and non-smokers in infertile couples. Fertil Steril 2003;79(2):287-91.

8. Sofikitis N, Miyagawa I, Dimitriadis D, et al. Effect of smoking on testicular function, semen quality, and sperm fertilising capacity. J Urol 1995;154(3):1030-4.

9. Muthusami KR, Chinnaswamy P. Effect of chronic alcoholism on male fertility hormones and semen quality. Fertil Steril 2005;84(4):919-24.

10. Guyton AC. Textbook of Medical Physiology. Philadelphia, USA: WB Saunders and Company Publishers 1981:9721004.

11. World Health Organisation. 2010 WHO Laboratory manual for the examination and processing of human semen. $5^{\text {th }}$ ed. Cambridge: Cambridge University Press.

12. Emokpae MA, Uadia PO, Omale-Itodo A, et al. Male infertility and endocrinopathies in Kano, Northwestern Nigeria. Annals of African Medicine 2007;6(2):64-7.

13. Zabul J, Mierzejewski W, Rogoza A. Usefulness of examining gonadotropin hormones and testosterone in men with abnormal semen. Ginekol-Pol 1994;65(2):71-4.

14. Bergmann M, Behre HM, Nieschlag E. Serum FSH and testicular morphology in male infertility. Clin Endocrinol (Oxf) 1994;40(1):133-6.

15. Kretser DM. The management of infertile male. Clin Obstet Gynaecol 1974;1(2):409-27.

16. Sultan C, Craste-de-Paulet B, Audran F, et al. Hormonal evaluation in male infertility. Ann Biol Clin (Paris) 1985;43(1):63-6.

17. Weinbauer GF, Nieschlag E. Gonadotropin control of testicular germ cell development. Adv Exp Med Biol 1995;317:55-65.
18. Subhan F, Tahir F, Ahmad R, et al. Oligospermia and its relation with hormonal profile. J Pak Med Assoc 1995;45(9):246-7.

19. Babu SR, Sadhnani MD, Swarna M, et al. Evaluation of FSH, $\mathrm{LH}$, and testosterone in different subgroups of infertile males. Indian Journal of Clinical Biochemistry 2004;19(1):45-9.

20. Bhale DV, Mahat RK. Evaluation of LH, FSH, and testosterone in infertile males. International Journal of Recent Trends in Science and Technology 2013;9(2):23840.

21. Hopkinson CR, Mauses J, Schenk B, et al. Some interrelationship between plasma levels of $\mathrm{LH}, \mathrm{FSH}$, oestradiol-17b, androgens, and semen analysis data in male infertility patients. Andrologia 1977;9(3):216-32.

22. Anderson RA, Wallace EM, Groome NP, et al. Physiological relationships between inhibin $\mathrm{B}$, follicle-stimulating hormone secretion, and spermatogenesis in normal men and response to gonadotropin suppression by exogenous testosterone. Hum Reprod 1997;12(4):746-51.

23. Samal S, Dhadwe K, Gupta U, et al. Epidemiological study of male infertility. Indian Medical Gazette 2012.

24. Jensen TK, Hjollund NHI, Henriksen TB, et al. Does moderate alcohol consumption affect fertility? Followup study among couples planning first pregnancy. Br Med J 1998;317(7157):505-10.

25. Durphy BC, Barratt UR, von Tongelen BP, et al. Male cigarette smoking and fecundity in couples attending and infertility clinic. Andrologia 1991;23(3):223-5.

26. Dhaliwal LK, Gupta KR, Majumdar S. The need for clinical evaluation and semen analysis of infertile men. Int J Fertil Womens Med 2000;45(3):232-5.

27. Kalyani R, Basavaraj PB, Kumar ML. Factors influencing quality of semen: a two-year prospective study. Indian J Pathol Microbiol 2007;50(4):890-5.

28. Durphy BC, Barratt CL, Cooke ID. Male alcohol consumption and fecundity in couples attending an infertility clinic. Andrologia 1991;23(3):219-21.

29. Tsujimura A, Matsumiya K, Takahashi T, et al. Effect of lifestyle factors on infertility in men. Arch Androl 2004;50(1):15-7.

30. Soares SR, Simon C, Remohi J, et al. Cigarette smoking affects uterine receptiveness. Hum Reprod 2007;22(2):543-7.

31. Ramlau-Hansen CH, Thulstrup AM, Olsen J, et al. Parental subfecundity and risk of decreased semen quality in the male offspring: a followup study. Am J Epidemio 2008;167(12):1458-64. 